2010

\title{
Meeting the Needs of Global Companies Through Improved International Business Curriculum
}

Kathy L. Milhauser

Tim Rahschulte

George Fox University, trahschulte@georgefox.edu

Follow this and additional works at: http://digitalcommons.georgefox.edu/gfsb

Part of the Business Commons

\section{Recommended Citation}

Milhauser, Kathy L. and Rahschulte, Tim, "Meeting the Needs of Global Companies Through Improved International Business Curriculum" (2010). Faculty Publications School of Business. Paper 34.

http://digitalcommons.georgefox.edu/gfsb/34 


\title{
Meeting the Needs of Global Companies Through Improved International Business Curriculum
}

\author{
KATHY L. MILHAUSER \\ School of Management, City University of Seattle, Bellevue, Washington, USA \\ TIM RAHSCHULTE \\ School of Business, George Fox University, Newberg, Oregon, USA
}

\begin{abstract}
The global workplace requires specific knowledge, skills, and abilities on the part of workers. There is a growing body of research indicating a gap between the global industry demand for skills and the bigher education system's ability to supply that demand. Leveraging the work from Yu, Guan, Yang, and Chiao (2005) and Prestwich and Ho-Kim (2007), this study investigated this gap. The sample included global leaders of Fortune $500 \mathrm{com}$ panies. Exploratory in nature, the primary purpose of this study was to understand the needs of global business organizations that form the hiring market for international business graduates. The findings bighlight the gap between the topics being taught by educators and the skills actually needed by the target international businesses. This information is relevant to the challenges facing global businesses as well as higher education institutions and provides insights into improvements for the good of both industries and especially the students aiming for careers in global organizations.
\end{abstract}

KEYWORDS international business, curriculum, globalization, product management, MBA curriculum

Address correspondence to Kathy L. Milhauser, City University of Seattle, School of Management, 11900 Northeast First Street, Bellevue, WA 98005, USA. E-mail: kathym@ cityu.edu. 


\section{INTRODUCTION}

Globalization has been described as the sense that the world is becoming smaller and our perspective broader (Friedman, 2007). Essentially, globalization refers to the trend toward organizations crossing economic and geographic boundaries and expanding from a local or regional perspective to a global one (Bhagwati, 2004). The amount of focus currently being placed on globalization is due to events and innovations in recent years that have served to accelerate the progress and awareness of globalization. For instance, technology has increased our ability to interact as a global society in many aspects of our lives and has specifically facilitated the accomplishment of business across geographic boundaries (Faulkner, 2002; Gilpin, 2000; Micklethwait \& Wooldridge, 2000). Additionally, economic markets and national governments have fueled the interconnectivity of the world thus creating the means for greater levels of globalization (Martinelli, Rahschulte, \& Waddell, 2010). Globalization has not emerged from an immediate occurrence, but rather from activities spanning centuries. Today, opportunities abound with the globalization trend, but so too do challenges.

The global trading opportunities available for all organizations in the increasingly accessible global workplace are immediately challenged by the demand for new knowledge, skills, and abilities among individuals in the workforce. This organizational opportunity and challenge is consequently an opportunity and challenge for educators to support the needs of global companies (Prestwich \& Ho-Kim, 2007). While shifts in our economic and political environment continue to cause instability in the global workplace, it is expected that individuals will increasingly look toward international business (IB) education as a way to differentiate themselves in the global job market, thus addressing the needs of employers worldwide. This trend is expanding from the developed world to developing nations such as India, Russia, and China, as students strive for an IB education that is accessible through study abroad programs and in underdeveloped markets where the Internet is making online education available to nearly everyone around the globe (Lefrere, 2007).

Traditional approaches used to develop an IB-focused curriculum have typically and simply been to provide add-on courses and experiential activities to existing MBA programs (Manuel, Shooshtari, Fleming, \& Wallwork, 2001). With the convergence of increasing demand for IB education, the accessibility of online programs exacerbating competitive pressures, and the sense of urgency on the part of potential students and companies, there are significant opportunities for universities who can embrace new approaches to meeting these needs. The traditional focus on content and delivery may not suffice for these universities and the markets they support. The ability to examine a changing global landscape and prepare students for future careers that are still not completely understood is going to require new approaches to program development and design (Vincent-Lancrin, 2004). 
There is evidence that quality IB education can be linked to positive results as measured by organizational performance (Beamish, 1988; Reynolds \& Rice, 1988; Zimmerman \& Fey, 2001), thus suggesting that universities work with global industry leaders to develop effective curriculum that, when executed properly, develops the knowledge, skills, and abilities of students entering the global workplace. These findings and suggestions have led to the investigation of IB education (Yu, Guan, Yang, \& Chiao, 2005). However, while many research studies have been conducted into the specific knowledge, skills, and abilities needed in international business, there is little evidence supporting an adequate response to this gap by IB programs (Prestwich \& Ho-Kim, 2007). Further, there is a growing body of research indicating the gap between the global industry demand for skills and the higher education system's ability to supply that demand has grown even broader in recent years (Yu et al., 2005). This study furthers the investigation into this gap by examining the degree to which graduate programs are satisfying the needs of organizations doing international business. The study is exploratory in nature and was designed to open a dialogue with leading international business practitioners in a number of topic areas. The factors forming the framework for the study include:

- the most important knowledge, skills, and abilities for graduates entering the global market;

- the perception of global leaders regarding the ability of universities to meet the demands of their organizations; and

- the approach that universities are deploying to partner with leading global organizations to design more effective programs and curriculum to address the needs of global business organizations.

Inquiry relative to these factors and this study at large provides pertinent information furthering the existing body of knowledge related to the gap between the skill needs within global business organizations and the higher education industry's readiness to bridge that gap. Moreover, this inquiry is relevant to the challenges facing global businesses as well as higher education institutions, and could ultimately provide insights into improvements for the good of both industries as well as the students aiming for careers in global organizations. Before detailing the findings, it is prudent to outline related literature and the research method. Both are offered immediately hereto with the literature review outlining research pertaining to the current state of graduate and IB-focused education. The review begins with general trends affecting business education and then focuses on research that has indicated gaps specifically in the international business setting. Research into the perspectives of business leaders, educators, and business students is introduced, as well as responses to curriculum development and program design that have been initiated in response to this need. 
Concern has grown in recent years related to the ability of universities to meet the needs of students and companies in a changing global work environment. In 2002, the American Council on Education embarked on an initiative to address the needs for global competence. The Council's report indicated, "Our future success or failure in international endeavors will rely almost entirely on the global competence of our people" (American Council on Education, 2002, p. 2). The study concluded that universities in the United States were not ready to meet that challenge.

As of 2004, the MBA degree was the second most frequent degree conferred in the United States, with an increase from 3,000 degrees awarded in 1955 to 100,000 degrees conferred in the year 2000 (Jain, 2008). As businesses have become more global in recent decades, most MBA programs have modified curriculum to include a global focus. The Institute of International Education reported in 2007 that enrollments in U.S.-based program rose dramatically. The demographics of students also shifted, with students from India being the largest pool of international students studying in the United States. This trend continued in 2008 with $57 \%$ of U.S.-based universities noting increases in overall international student enrollments (Institute of International Education, 2007, 2008). Additionally, as a response to the recent global financial crisis, U.S. federal stimulus funds intended to support increases in the education level of all Americans have begun to flow into the U.S. education system with the potential for $\$ 100$ million in investments between 2009 and 2016. The U.S. Department of Education predicts that adult learners pursuing degree completion and graduate education will be the fastest growing segment in the higher education market in this timeframe (Eduventures, 2009).

The increasing number of students choosing the MBA degree to support their needs for graduate business education has caused examination into the content and value of these degrees and the conclusion by many that the value of the degree may be in question (Andrews \& Tyson, 2006; Bennis \& O’Toole, 2005; Mintzberg, 2004; Pfeffer \& Fong, 2002). As growing numbers of global students choose to study in the United States, it is expected that the need for focus on the value of these studies to develop the skills for a future global workplace will become even more acute.

Many researchers have studied the skills and competencies needed to effectively lead teams in the global environment (Malone, 2004; Mohammed \& Angell, 2004; Thomas \& Bostrom, 2007). Of note, Ancona and Bresman (2007) furthered Gladstein's (1984) study of over 100 sales teams in the telecommunications industry in an effort to understand the skills needed for global team performance. Their findings suggested the need for new competencies to lead global teams. Their findings included the need for (a) an appreciation of differences in cultural perspective, (b) leveraging diversity and conflict to optimize team performance, (c) enhanced decision-making 
skills for complex environments, and (d) facilitation skills for leading teams in distributed locations.

Arthur and Rousseau (1996) introduced the concept of a career without boundaries as companies experience increasing demands for employees who can work independently in the global environment. These global careerists include individuals who accept expatriate assignments for specific organizations, those who work in the globally distributed environment and travel frequently to locations abroad, and a new emerging breed of global careerists who work as independent consultants in foreign countries (Suutari \& Smale, 2008). This growing diversity and independence in the role of the global careerist is expected to require a redefinition of the psychological contract between employer and employee and enhanced knowledge, skills, and abilities.

Contributing to the research related to new competencies for global careerists, Hardin, Fuller, and Davison (2007) conducted a study of workers performing in global teams and found that most report less confidence in their ability to perform their work effectively in a diverse and distributed global environment. Hardin's research indicated that new approaches to teamwork and communication processes may be needed. Further, Kickul, Lester, and Belgio (2004) suggested that new approaches to cross-cultural cooperation are also needed in the evolving global workplace. These findings place new demands on universities to think differently about preparing students for international careers specifically and the global market in general.

In the past decade, efforts have been made by higher education organizations, and their accrediting bodies to some extent, to differentiate business degrees that focus on IB education through elements in their curriculum, including topics covered and approaches to instruction (Manuel et al., 2001). Surveys of content in leading IB programs indicate that topics relevant to IB are generally added on to existing management curriculum (Delaunay \& Blodgett, 2005; Manuel et al., 2001; Prestwich \& Ho-Kim, 2007; Tuleja, 2008). These content modifications are often additionally supported or supplemented by study-abroad or foreign immersion experiences and innovative teaching methods to enhance the experience of the student (Delaunay \& Blodgett, 2005; Genc, 2008; Oblinger \& Oblinger, 2005; Tuleja, 2008). Concerns remain, however, as to the effectiveness of these approaches and these degrees as graduates enter the global workplace.

As the student is generally considered the end customer of education programs, research has also been conducted into their needs and perceptions of program effectiveness. Sulaiman and Mohezar (2008) gathered data from 53 graduates of an IB program. The findings from their study indicated an overall high sense of satisfaction on the part of students with their grasp of the skills taught in the program. However, there is still concern regarding the gaps between what students learn and what is needed to be successful in international business careers. "Interestingly, it was also found that graduating students do not acknowledge much exposure to cross-cultural sensitivity 
and awareness" (p. 7), which is one of the key success criteria in hiring IB graduates as noted by Angeline (2001).

Using a survey to gather data on student perception of cross-cultural knowledge before and after their China immersion trip, Tuleja (2008) also identified the need for better cultural understanding on the part of students in graduate and IB-focused study-abroad programs. The findings indicated that deeper and more sustained immersion in culture was perceived by students as necessary to broaden their perspectives. This led Tuleja to question whether cross-cultural competency can be taught, or must be learned over time through diverse and repeated experiences. Chick (1990) specifically noted that intercultural communications cannot be taught effectively as a body of knowledge, but rather must be learned through immersion and experiential reflection.

Genc (2008) described an integrative approach to teaching international business skills, based on the international business program at the University of Idaho. Genc's findings indicated that students' own efforts were the greatest contributors to their learning, but that integration of core concepts throughout the program enhanced meaning for the students. Further, Genc's findings suggested that a blend of instructional methods, including individual and team-based activities as well as blending IB education with practical field-based experiences, was found to enhance student learning and overall satisfaction with their program.

Cox, Minter, and Thompson (1995) emphasized the benefit of students having a corporate-university partnership. They describe the need for a board of directors approach that brings CEOs together with faculty advisors and students. This approach provides a simulated corporate board experience for students and also an opportunity for partnership between corporate representatives and universities.

These studies are consistent with a message echoed by Dolby and Rahman (2008) who noted that "Over the past 10 years, the pressure to 'be international' and to 'internationalize' has dramatically intensified in all aspects of education" (p. 676) and therefore a review is needed to ensure that the correct competencies and instructional methods are being addressed in IB education today. The majority of research into the higher education response to a global skill gap has focused on the content of leading programs, the accreditation requirements of controlling bodies, and the perception of students enrolling and learning in the programs. Less evident is any significant body of research into the needs of leading companies as the global environment continues to change at an accelerating pace. Data from studies on specific schools and markets provide support for this growing need for research (Cox et al., 1995; Delaunay \& Blodgett, 2005; Prestwich \& Ho-Kim, 2009; Sulaiman \& Mohezar, 2008). In some cases, these studies have further illustrated the gap between student perceptions of the skills they need to be successful and company and industry assessment of the skills needed in the immediate future (Angeline, 2001). 
Attempting to address the skill gap from a company specific perspective, Yu and collegues (2005) conducted an exploratory study of international business needs in Taiwan that resulted in findings in three areas: (a) the skills firms look for when filling positions, (b) the degree to which higher education institutions are able to satisfy the needs of the business community, and (c) the top seven most important skills for international managers, as perceived by the participants in the study. The skills determined as most important to Taiwan international business leaders were then mapped on a Management Opportunity Grid, illustrating the importance of each skill along the $\mathrm{Y}$-axis and the degree of satisfaction with students that Taiwan business leaders had hired along the X-axis. The researchers noted limitations to this study, namely that the findings would not be appropriate to generalize beyond the scope of their study in Taiwanese business. Further, the skills noted in the Management Opportunity Grid were relevant when the study was conducted in 2005, but may have changed since that time as the global business environment has changed.

With these limitations in mind, Prestwich and Ho-Kim (2009) furthered the work of Yu et al. (2005) by conducting a study of international businesses based in Minnesota. They surveyed their sample with questions related to the need for international business skills derived from the topic and section headings of textbooks typically used in international business curriculum. Their findings indicated a significant gap between the topics being taught and the skills actually needed by international businesses. Only 5 out of 31 topics being taught were indicated as essential for success in international business roles by members in the sample.

The aim of this study was to validate the skill gap suggested by Prestwich and Ho-Kim (2007) using a different sample, thereby addressing one of their study's limitations. This study also explored the experience global companies have had with international business graduates and explored best practices that they have experienced with education partnerships to develop global workers with the essential skills for their organizational challenges. Further, this study aimed to continue the inquiry documented in the literature review related to the needs of global companies and students, as well as emerging practices in IB education intended to serve those needs in an increasingly dynamic global business environment.

\section{METHOD}

Exploratory in nature, the primary purpose of this study was to understand the needs of global companies that form the hiring market for international business graduates. To do so, this study leveraged the work of Prestwich 
and Ho-Kim (2007) by deploying the same survey questions to further explore the specific international skills gap from a global company perspective.

\section{Sampling}

The sample was purposefully determined. Patton (2002) defined purposeful sampling as the process used to "select information-rich cases strategically and purposefully" (p. 243). Specifically, within the category of purposeful sampling, a criterion-based strategy was used to identify the initial interviewees. The reason for this strategy was to ensure expert participation from those with information-rich experiences appropriate to yield data that can be compiled into a practical implementation strategy for use by those in academia and industry.

The criterion for the sample used in this study was global organizations recognized as leaders in their sectors and with international offices that hire employees for international assignments as well as global management roles. Specifically, focusing on globally mature market sectors led to the review of the top global companies with business operations in at least 50 countries, more than 10,000 employees, and with revenues that place the company within Fortune 500's Top Industries (Fortune 500, 2009). Companies that fulfill these criteria are expected to be most dependent on a high level of skill in international business due to their scope, size, and global reach.

While the names will remain confidential, the companies included in this study were all global leaders in their industries with headquarters in the United States. All of the organizations in this study have offices and operations in Asia, Europe, and the Americas and frequently deploy employees to serve in these locations. Importantly, they also hire employees to work in their central headquarters in the United States as leaders of global business units. Each organization is listed by Fortune magazine as one of America's largest companies, and is ranked as the top revenue-generating company within its specific industry as defined by Fortune (Fortune 500, 2009).

The sample consisted of nine global business leaders from three separate companies, with a diverse set of organizational functions including product engineering, manufacturing, international trade, information technology, and human resources. With the organizations and functions identified, the means to determine the practitioners to interview was needed. A criterion sampling (Patton, 2002) approach was used to select the individuals to survey for this study. Each of the participants had worked in a global business environment for at least 10 years and influenced at least 100 hires during his or her tenure in the organization. These practitioners are commonly known as expert informants and participants-in-action. Flick (2002) noted that good informants have knowledge and practical experience of the phenomenon in question, are articulate, and have time to participate and contribute to the study. Hassard (1991) noted, "The social world is best understood from the view point of the participant-in-action" (p. 277). As such, these practitioners 
TABLE 1 Years of Global Management Experience

\begin{tabular}{lcc}
\hline Years of global management experience & Respondents & Distribution \\
\hline $10-15$ & 2 & $22 \%$ \\
$16-20$ & 3 & $33 \%$ \\
More than 20 & 4 & $45 \%$ \\
Total & 9 & $100 \%$ \\
\hline
\end{tabular}

TABLE 2 Number of Hires Influenced During Career

\begin{tabular}{lcc}
\hline Number of hires influenced & Respondents & Distribution \\
\hline $100-200$ & 2 & $22 \%$ \\
$201-300$ & 4 & $45 \%$ \\
$301-400$ & 1 & $11 \%$ \\
$401-500$ & 1 & $11 \%$ \\
More than 500 & 1 & $11 \%$ \\
Total & 9 & $100 \%$ \\
\hline
\end{tabular}

are experts in their organizations relative to IB and sufficient to serve as the research sample. Tables 1 and 2 illustrate the years of experience and hiring influence represented by the participants in this study.

While the sample size of 9 participants from three companies is small, it did allow for a broad range of perspectives on international business skills needed within the organizations that represent three diverse industries doing business in over 50 countries. The organizations were intentionally selected for their diverse industry perspectives and broad reach. This approach allowed for a broad perspective on the needs of international business organizations that span multiple industries, a broad range of countries and cultures, and with the added perspective of how these needs have evolved during the tenure of the participants, and thus appropriate for this study. According to Josselson and Lieblich (as cited in Josselson, Lieblich, \& McAdams, 2003), the sufficiency of any sample "is inversely proportional to the intensiveness of the study" (p. 268). This means that if the inquiry is deep in context and meaningfully long and intensive, while being observed highly in detail and multi-layered ways that yield superlative data, relatively few interviews are needed. Of paramount importance is to have enough data to represent the richness and diversity of the phenomenon, but not so much as to be overwhelmed (Kvale, 1996). Generally, Josselson and Lieblich advise at least 5 and no more than 30 interviews are required in qualitative studies. Therefore, again, the sample is recognized as small, but sufficient.

\section{Data Gathering}

Data were gathered through a series of semi-structured interviews. A set of questions was prepared based on the questionnaire used by Prestwich and 
Ho-Kim (2007). The questionnaire included questions in three areas: (a) the importance of various skills for global management careers, (b) opinions and suggestions related to the match between skills needed and skills acquired by students from international business programs, and (c) experience with any specific university in the design or review of their international business program. The final question related to experience with specific universities was intended to provide insight into any university partnerships that might exist or be emerging related to these questions.

\section{Data Analysis}

The interviews were transcribed by the primary researcher and then analyzed using a content analysis method so that emerging themes and categories of responses could be recognized, coded, and interpreted. An additional researcher reviewed the interview transcripts and the results of the content analysis to ensure inter-rater reliability.

\section{FINDINGS}

The findings of this study supported the notion that there is a need for tighter integration between the needs of global businesses and the focus of IB curriculum. Participants indicated a sense that the knowledge, skills, and abilities on the survey, as previously determined requisite by Prestwich and Ho-Kim's (2007) research, seemed somewhat outdated and fairly academic in perspective. This suggests the need for the knowledge, skills, and abilities to be refreshed to match the dynamic nature of today's global business environment. For example, similar to Prestwich \& Ho-Kim's findings, general skills were specified as essential by almost all global business leaders in this study. Interviewees repeatedly indicated that there are basic skills that they expect IB graduates to possess, including the ability to (a) use common computer tools and systems, (b) communicate effectively, and (c) work effectively in teams. These skills were noted to be important of all graduatesthose from an IB-focused degree or otherwise. The fact that these skills formed the focus area defined as general skills in the study was of greater concern to the participants, who felt that higher level skills should be expected of IB graduates; and that basic computer, communication, and team skills were an expectation of any hire in contemporary business. Also similar to the Prestwich and Ho-Kim findings, participants in this study were less concerned with specific functional skills related to international business and trade rather than the broader and more comprehensive competencies identified as "Other Business" by the survey instrument, including (a) cultural awareness, (b) leadership competency, and (c) a focus on business ethics. 


\section{Most Essential Knowledge Areas}

Table 3 lists the top knowledge areas identified by the participants in this study, with their corresponding categories from the original study conducted by Prestwich and Ho-Kim (2007). The knowledge areas rated most essential for hire by the participants in this study were all from the categories labeled "Other Related Business" and "Other General Skills." All participants rated the following four knowledge areas as essential from these two categories: (a) business ethics, (b) cultural differences, (c) teamwork, and (d) presentation skills. The legal/intellectual property knowledge area, also from the "Other Related Business" category, was noted as essential by 8 out of the 9 participants. One other highly rated knowledge area from the "Other General Skills" category was writing skills, which was also deemed essential by 8 out of the 9 participants.

As for the knowledge areas in the "International Economics" and "International Business Skills" categories, strategic planning is the only knowledge area indicated as essential by more than $75 \%$ of participants; it was rated essential by 7 of the 9 participants surveyed. The full list of knowledge, skills, and abilities used in this study with the corresponding responses from all participants on each topic area can be found in the Appendix at the end of this article.

Due to the nature of the semi-structured interviews, there were opportunities for participants to add comments and highlight areas of concern in alignment with their responses during the interview process. Although the knowledge area "cultural differences" was included on the survey and received an "essential" rating by all 9 participants, it was also the knowledge area most often classified as the most essential through participant comments. Additionally, when asked if there were any knowledge areas missing from the survey, "cultural competence" was mentioned by 8 of the 9 participants. Specifically, one participant indicated concern over the treatment of culture in coursework, stating, "I don't know if I would use the word differences" and indicated a desire for "cultural tolerance, awareness of diversity, respect for cultural variation, cultural literacy, and intercultural communication" as knowledge areas under- or un-represented by graduate and IB programs

TABLE 3 Most Highly Rated Knowledge Areas

\begin{tabular}{|c|c|c|c|c|c|}
\hline Knowledge area & Survey category & Essential & $\begin{array}{c}\text { Nice } \\
\text { to have }\end{array}$ & $\begin{array}{c}\text { Not } \\
\text { needed }\end{array}$ & Total \\
\hline Business ethics & Other related business & 9 & 0 & 0 & 9 \\
\hline Cultural differences & Other related business & 9 & 0 & 0 & 9 \\
\hline Teamwork & Other general skills & 9 & 0 & 0 & 9 \\
\hline $\begin{array}{l}\text { Legal areas (IP, distributor } \\
\text { agreements) }\end{array}$ & Other related business & 8 & 0 & 1 & 9 \\
\hline Writing skills & Other general skills & 8 & 1 & 0 & 9 \\
\hline Strategic planning & International business skills & 7 & 2 & 0 & 9 \\
\hline
\end{tabular}


in their experience. Another participant called cultural awareness "one of the lost pieces in business teaching"-referring to culture from a national, functional, corporate, and set of unique characteristics' perspective. Another participant stated, "Among the best and brightest executives, cultural differences are what's killing them." This thread of cultural awareness concern was also evident in the discussion of other knowledge areas with participants calling for culturally diverse approaches to (a) teamwork, (b) communication, (c) collaboration, (d) how culture impacts business, (e) cultural aspects of organizational dynamics and behavior, and (f) how legal systems are influenced by culture. One participant indicated that "cultural differences are huge" and lamented that "we get ourselves in so much trouble" due to lack of cultural sensitivity.

The second knowledge area that stimulated frequent discussion was business ethics. The topic of business ethics often resulted in deeper discussion on the part of several participants, second only to cultural differences. One participant indicated, "Business ethics trips us up" and stated that "Global managers need to learn to exercise better judgment, especially when working with different cultures and countries who have diverse ethical frameworks." Like the culture topic, business ethics was one that was not easily confined to a single topic. Participants felt that universities should focus more on value systems, helping students find their own moral compass and skills for self-awareness, emotional intelligence, and reflection to help keep their behavior in alignment with their belief system. Interview discussions included the need for global managers to act with autonomy and develop the ability to discern what is and is not right in a variety of business situations.

A related area of discussion involved dealing with politics in various situations and settings and developing the "judgment needed to operate ethically in alignment with an individual's personal values as well as the values of his or her organization." One participant noted that, "If you don't operate with ethics, you put yourself and your company at risk." Another referred to the perception that the "ethical line is moving" in recent years and that "more and more people are beginning to react with their own short-term interests ahead of the needs of their organizations or their own long-term benefit."

\section{Missing Knowledge Areas}

In addition to the areas of cultural awareness and business ethics that naturally emerged as most essential in discussion, several knowledge areas were identified as missing from the original survey. Specifically, skills such as the (a) ability to network and build relationships, (b) ability to partner with foreign businesses, (c) management of non-Americans and cross-cultural management, (d) general global awareness, (e) organizational dynamics, (f) knowledge management, $(\mathrm{g})$ emotional intelligence, and (h) communication skills were 
mentioned. It should be noted that while both presentation skills and writing skills were rated essential, discussion data indicated that both of these skills fit within the broader topic of overall communication competence. Participants considered writing and presentations skills as part of a total communication skills knowledge area and commented on the need for more focus on communication skills in the global workplace. The most frequently mentioned missing skills were (a) the ability to build and sustain relationships; (b) the ability to manage across cultures and geographies (i.e., distributed teams); and (c) communication skills in the multi-cultural, distributed environment.

\section{Comparison to Previous Study}

The knowledge areas found to be most essential for hiring in the Prestwich and Ho-Kim (2007) study were the general skills of (a) writing, (b) teamwork, (c) computer software, (d) presentation skills, and (e) project leadership. While two of these knowledge areas were identified as essential in this study-teamwork and presentation skills-they were included only as components of a broader category that participants referred to as communication or collaboration skills. The participants of the current study indicated computer skills as a basic requirement that is expected as a minimum for hire in any professional environment, but not one that would act as a hiring differentiator. "I would be hard-pressed to hire someone without comfort with basic general (computer) skills," indicated one participant.

Similar to the participants in the Prestwich and Ho-Kim (2007) study, the participants in this study indicated that the international economics and business knowledge areas were important for forming a general knowledge base for the global manager. However, most in this study indicated that their organizations had training programs and support services to assist the global manager with functional expertise in these areas, and that they were not as essential as mastery in domains such as cultural sensitivity and business ethics. Also similar to Prestwich and Ho-Kim (2007), language skills were deemed important but not essential for hire by the participants of this study. Several participants noted that skills in the appropriate languages for an expatriate assignment or international role were often a differentiator for hiring decisions, but that they would not prioritize language over the knowledge areas they had deemed essential.

\section{Perception of Value}

In addition to rating the knowledge, skills, and abilities essential for hire, participants were asked two questions intended to probe their perception of the value of IB-specific degrees. For the most part, participants indicated a general lower level of demand for an IB degree in favor of experience and competence in the knowledge areas identified as most essential. "It's not 
just about taking a leadership class . . . it is hard to replace experience," indicated one participant. Another participant recounted a story of one of his employees who came to him for advice about earning an MBA. He told his employee that he did not need an MBA for success in their organization, but instead recommended an internal leadership development program to help the individual gain leadership experience and perspective. Another participant was insistent that "MBA programs do nothing to prepare you to manage in the global environment" and that they were "outdated in general." This individual felt that what global managers really needed to excel was to understand how companies operate, and that immersion and customization of learning in the target environment was the only way to gain that understanding. These comments are interesting in that when asked about IB programs, the participants equated that to (MBA) graduate programs. As noted, it was perceived by participants that traditional MBA programs have attempted to address the need for global focus by adding on to existing curriculum rather than redesigning programs to integrate company and market needs to adequately address global market pressures.

Comments were also made related to the ability to learn about IB in U.S.-based programs. Potential students were urged to "look closely at issues such as student diversity and the amount of time that faculty have spent outside the U.S.," noted one participant. "China, China, China," stated another participant who has spent over 20 years working outside the United States for her company. "You can't learn about international business inside the U.S.," she claimed. Another participant expressed concern over the consequences of the cultural gap, indicating that "there is no replacement for immersion in the local environment and culture in order to be successful." Referring to foreign business partners, he indicated, "either they decide we're apes and pull the wool over our eyes_or they disengage (and display) bad behavior." This participant advocated immersion in the target culture where the manager would be working, with mentoring from a more experienced global manager.

Other participants were less passionate about the need for cultural immersion, but were still concerned about the ability for graduates to apply their IB skills in an authentic environment. "Universities in general do not prepare students adequately for [global] application," stated one participant, and "they are getting the tactical management (skill) but not how to be a leader." These participants felt that potential global managers needed time to be ready and to develop the competencies for success and agreed that focused mentoring is critical.

\section{Industry/Higher Education Partnerships}

The final question asked of all participants in the study was whether they had any experience in the design or review of an IB program. This question 
was intended to probe for experience with any specific university that the participant's organization might have partnered with to develop their global managers. While several participants indicated interest and respect for specific schools they were affiliated with, none of the schools were mentioned more than once, and for the most part the references were based on personal, and not professional, experience. While this is a small sample, it is still interesting that 9 highly tenured global leaders from Fortune 500 companies would not mention a school that was known for its international business curriculum or industry partnership reputation.

In summary, the findings of this study suggest that there may be a need for a refresh in the knowledge, skills, and abilities that form the curriculum for IB programs. Further, with global business evolving rapidly there might be an even greater need for new approaches to curriculum design, review, and adjustment to maintain currency with global business needs. Both findings are further discussed in the next section.

\section{DISCUSSION}

Knowles, Holton, and Swanson (2005) suggested approaching the design of learning for adults from a process as well as content perspective. A content approach involves (a) deciding what needs to be learned, (b) developing a plan to teach the topic, and then (c) executing the plan with a measurement approach to ensure that the learner understands what was taught. In contrast, a process approach involves (a) engaging stakeholders (students and industry in this case) in a dialogue regarding topics worthy of exploring, (b) creating a climate for learning, (c) formulating learning objectives, (d) facilitating student exploration of the topics, and then (e) evaluating student achievement of outcomes while re-diagnosing the learning needs. Knowles suggested that this latter, andragogical approach is not only needed, but of the two perhaps a more appropriate model for adult learners; but more likely to be a sustainable model in topic areas where content is rapidly evolving.

The top two business knowledge areas indicated as essential in this study were cultural differences and business ethics. The cultural differences learning need was expanded to include cultural tolerance, awareness of diversity, respect for cultural variation, cultural literacy, and intercultural communication. Further, participants suggested integration of cultural awareness in topics such as teamwork, communication, collaboration, and general management skills. Business ethics was also indicated as essential, and linked to broader topics such as individual value systems, organizational politics, and culture.

One reason for the difference in essential knowledge topics between this study and the previous studies (Prestwich \& Ho-Kim, 2007; Yu et al., 2005) might be the time elapsed between studies and the changes in the 
global business landscape over the past few years. It is expected that these changes will continue as the ability and demand for organizations to globalize their operations and approaches continues to grow (National Intelligence Council, 2008).

In terms of process design for learning, participants in this study highly valued programs that include immersion in diverse cultures and mentoring by more experienced global managers. Therefore, continuing to approach the development and delivery of curriculum from a content/topic perspective, which has typically been the approach with add-on courses, may not be the best way for universities to adapt to the changing global business environment. While cultural differences and business ethics lead the topics of concern on the minds of global managers today, that might change tomorrow. The participants of this study were immersed in the daily challenges of leading global business initiatives and represented current and relevant experience with the knowledge gaps in their organizations. If the content approach to curriculum and instruction is continued, it is likely that new gaps in knowledge will continue to emerge and perhaps go unnoticed by the designers of education programs, thereby developing ineffective and unprepared global managers. Therefore, a process approach with more frequent engagement with industry, more integration of curriculum topics, and deeper immersion in relevant and authentic global management learning experiences seems more likely to facilitate deeper learning and strengthen university-industry partnership to better supply graduates to meet the skill demands of companies.

University administrators as well as program and curriculum designers can view the process approach similarly to product management. Product companies spend significant and continual time and effort understanding the needs of their markets and (potential) customers. This effort yields details of expectations and requirements. Relative to business education customers, the potential students and perhaps more importantly the hiring companies of graduates espouse talent gaps, issues, and concerns with the current product-the curriculum and its associated resources. This knowledge can be used throughout the product cycle-that is the planning of the product, design and development of the product, execution or delivery of the product, and the utility of the product-in an effort to meet the increasingly demanding and changing market. Indeed, keeping supply aligned with market demand is the expectation and value of products-the education industry is not too terribly different than any global products company in this regard. While nationally accredited agencies require "sound and upto-date courses/programs" (Distance Education and Training Council, 2010) that help students "deal effectively with critical issues in a changing global business environment" (International Assembly for Collegiate Business Accreditation, 2009) through a continuous curriculum management improvement process (Association to Advance Collegiate Schools of Business International, 2010) it is interesting that of the 9-person sample from global leading 
companies, none of them are aware of any private industry-educational partnership. Accrediting bodies, and more importantly educational institutions themselves, would increase their service, customer awareness, and effectiveness by further entrenching themselves in their communities through (more effective) advisory boards and business-led curriculum development committees. All accreditation bodies espouse the need for relevance and practical utility in curriculum. The accomplishment of such an expectation may never be reached-it is an ever-changing target rather than a destination. The process of this work, however, can be consistently deployed to realize optimal effectiveness. This process is akin to product management protocols. The more effective the process is the more effective the product will be. This effectiveness, by the way, is in turn realized by not only students and hiring companies, but importantly the university's faculty and administrators. As a product approach is used, faculty and administrators will recognize the value from integrating topics, collaborating with one another, and offering a more cohesive tightly bound solution rather than a loosely coupled series of courses.

One of the most disruptive forces in an academic classroom is the faculty. Adult students are interested in enrolling into a program curriculum that is administered as a whole product, rather than siloed classes. Just as the members from this sample noted the need to avoid viewing topics such as culture and ethics singularly, students too want an integrated whole rather than siloed topics and classes. The integration of concepts and curriculum is what Genc (2008) noted as the means to enhancing meaning for students. Integrating coursework as a whole demands a teamwork (among business advisors, university administrators, and faculty). Additionally, integrating coursework as a whole helps administrators with accreditation requirements due to its ingrained nature of determining planned outcomes, tracking performance via assessments, and making adjustments based on market data and performance measures. As such, when coursework is integrated it does not stand alone, but rather is linked to market needs. Further, this approach accomplishes Knowles et al.'s (2005) belief that adult learning should include both a content and process approach.

An integrated, outcomes-based approach can be used to ensure that high demand knowledge and skills areas such as those indicated in this study are embedded within program and course design processes (Kirstein, Fountain, \& Flores, 2009). In addition to designing the curriculum to address global market needs, students can be developed through planned pedagogy and andragogy to do the same. Measuring performance through assessments and outcomes serves as the data-driven means for continuous improvement. The key to this continuous improvement cycle is the consistent and managed input and reflection on fresh information from the market for which the program and courses have been designed. Maintaining strong partnerships with industry advisory board members can ensure that the program continues 
to be practical and relevant as the needs of industry change. Figure 1 illustrates a sample curriculum product process map. The map illustrates the market, which provides the educational institution data for its programs and specific courses. There is an overlapping partnership between advisory board members and university resources including program administrators and faculty. The evaluation, at the course and program level, provides reciprocating feedback on market demands and program and course effectiveness, thus creating a continual process.

Leveraging both process and content learning model variables, integrated programs are all about assessing needs and outcomes and then modifying resources appropriately. Students are assessed based on course and program assignments, which are linked to course and program outcomes. Course and program outcomes are assessed via faculty and advisory board members. Faculty should be assessed by students, peers, and program directors. You can think of this as a product cycle, which it is. With the integrated program approach to curriculum, the university can better plan, assess, and modify as appropriate how it develops students into effective practitioners to meet market needs.

Precedents do exist that demonstrate the value of corporate and university partnerships engaged in a process similar to that illustrated in Figure 1 (Cox et al., 1995; Genc, 2008; Jain, 2008). Universities that focus their curriculum development, review, and assessment on industry (and thereby student) need find that the process as well as product of that collaboration yields great benefit for all parties involved - the university, organization, and student. The process of collaboration helps to ensure the program of study is relevant and aligned to current industry needs, thus increasing the chances that the product - the student-developed will be embraced by industry and allow the university to benefit through relationships that enhance the perceptions

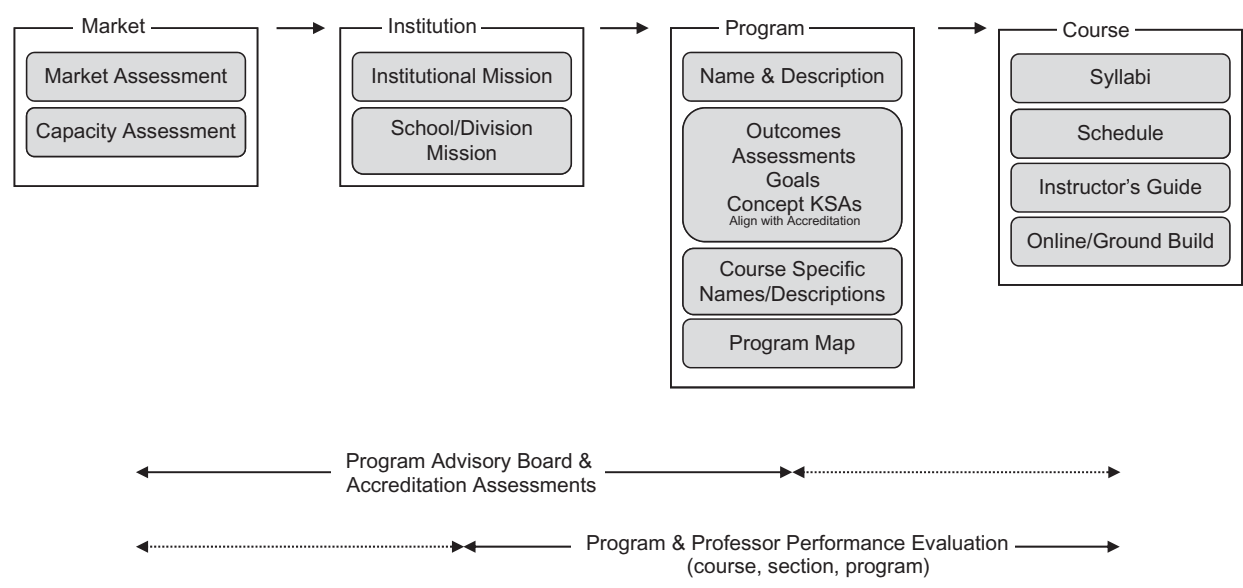

FIGURE 1 Sample Curriculum Product Process Map. 
of its relevance. Students benefit not only from the focus of this product development effort, but also by association with the organizations that have come together to advise and direct the program development. These relationships can result in opportunities for employees to become students through organizational buy-in. Additionally, students affiliated with the university frequently benefit through internships, job shadows, and association with the partnered organizations.

As noted, determining what exactly needs to change in the curriculum is not a onetime activity, but rather is a process of continuous analysis, reflection, and adjustment. The MBA degree, although modified in attempted to accommodate IB needs, has become ubiquitously associated with mastery in the business education community. While many might argue that a new graduate-level business/management degree is warranted, especially in light of the increasing acceleration of globalization and associated learning needs, we would suggest that the type of program or curriculum is less important than the process by which it is maintained. Ensuring that the curriculum is reviewed by industry in partnership with academia, infused with new ideas based on emerging industry needs, and delivered in richly integrated, interactive, and experiential methods helps to ensure continual "newness." In this way, universities can increase the chances that students will emerge from their programs of study not only ready, but in demand by industry partners.

\section{CONCLUSION}

The findings of this study indicate a potentially widening gap between the needs of industry and the knowledge, skills, and abilities forming the curriculum for IB programs. It came as no surprise to the participants in this study (all individuals engaged deeply in global business activities) that higher education, with a predominantly content-focused approach (Knowles et al., 2005), would be struggling to keep pace with industry.

Changes in the economic, legal, political, and cultural landscape of work-resulting in increasing geographic distribution of workers and all of the inherent complexities therein-are still relatively new in the history of organizations. As such, these challenges are just beginning to enter our consciousness as we look forward at how globalization will affect the workplace of tomorrow. The accelerated pace of globalization in recent decades would indicate that the trends we are experiencing are going to continue and even increase in pace. The National Intelligence Council (2008) predicts that the next 15 years will introduce "more change than continuity" as international powers continue to shift, introducing "the likelihood of discontinuities, shocks, and surprises" (p. 3). Leadership on the part of all major players in the shifting geopolitical landscape is likely to be a key indicator in the 
determination of global outcomes for business as well as political stability. Organizations that hope to remain competitive as globalization continues to evolve will need to focus on skills and competencies for leadership of their global and international teams.

The most critical role that higher education plays in the response to changes in the global context is to equip students with the skills they need to be productive in the workplace of the future. Partnering with industry in sustained focus on the knowledge, skills, and abilities required of tomorrow's leaders may be the only way for higher education to remain relevant and regain its value in the eyes of its ultimate customer-the global marketplace.

While this study did not uncover a leading university-industry partnership that has been successful in sustained curriculum evolution, it is likely that partnerships like this do exist. Further research focused into best practices in university-industry partnerships and documentation of case studies could add value to this ongoing discussion for all parties. Additionally, the development, implementation, and measurement of the effectiveness of models such as the one proposed in Figure 1 could provide opportunities for researchers to gather more extensive data on the value of integrated program development.

\section{REFERENCES}

American Council on Education. (2002). Beyond September 11: A comprehensive national policy on international education. Washington, DC.: American Council on Education, Center for Institutional and International Initiative.

Ancona, D., \& Bresman, H. (2007). X-teams: How to build teams that lead, innovate, and succeed. Boston, MA: Harvard Business School Publishing.

Andrews, N., \& Tyson, L. (2006). The upwardly mobile MBA. Strategy \& Business, $36,1-10$

Angeline, T. (2001). Management's perception of MBA graduates in Malaysia. Journal of Management Development, 20(3), 258-274.

Arthur, M. \& Rousseau, D. (1996). The boundaryless career: A new employment principle for a new organizational era. New York, NY: Oxford University Press.

Association to Advance Collegiate Schools of Business International. (2010). Eligibility procedures and accreditation standards for business accreditation. Tampa, FL: Author.

Beamish, P. W. (1988). A gap in the business curriculum? Canadian Business Review, 15(4), 28-30.

Bennis, W. G., \& O'Toole, J. (2005, May). How business schools lost their way. Harvard Business Review, pp. 96-104.

Bhagwati, J. (2004). In defense of globalization. New York: Oxford University Press.

Chick, J. K. (1990). Reflections on language, interaction, and context: Micro and macro issues. In D. Carbaugh (Ed.), Cultural communication and intercultural contact (pp. 253-258). Hillsdale, NJ: Lawrence Erlbaum. 
Cox, A. T., Minter, R., \& Thompson, A. F. (1995). A model for developing a university business partnership. Journal of Management Education, 19(2), 233-239.

Delaunay, C., \& Blodgett, M. (2005). A global MBA for tomorrow's global business leaders: Integrating best practice with Boston's locational advantage. Journal of Teaching in International Business, 17(1-2), 125-141.

Distance Education and Training Council. (2010). Accreditation handbook: Distance Education and Training Council. Washington, DC: Author.

Dolby, N., \& Rahman, A. (2008). Research in international education. Review of Educational Research, 78(3), 676-726.

Eduventures. (2009). Managing change on campus: Academic programs development and assessment. Boston, MA: Eduventures, Inc.

Faulkner, D. (2002). Strategy: Critical perspectives on business and management. New York, NY: Taylor \& Francis.

Flick, U. (2002). An introduction to qualitative research (2nd ed.). Thousand Oaks, CA: Sage.

Fortune 500. (2009). Our annual ranking of America's largest corporations. Retrieved from http://money.cnn.com/magazines/fortune/fortune500/2009/

Friedman, T. (2007). The world is flat. New York, NY: Picador.

Genc, I. (2008). Designing an integrated business curriculum with students' success in mind: An evaluation within the context of the IBC programme at the University of Idaho. International Journal of Management Education, 7(3), 81-86.

Gilpin, R. (2000). The challenge of global capitalism. Princeton, NJ: Princeton University Press.

Gladstein, D. (1984). Groups in context: A model of task group effectiveness. Administrative Science Quarterly, 29, 499-517.

Hardin, A., Fuller, M., \& Davison, R. (2007). I know I can, but can we? Culture and efficacy beliefs in global virtual teams. Small Group Research, 38(1), 130-155.

Hassard, J. (1991). Multiple paradigms and organisational analysis: A case study. Organisation Studies, 12(2), 275-299.

Institute of International Education. (2007). International student enrollment in U.S. rebounds. In Open Doors annual report on international education. Retrieved from http://opendoors.iienetwork.org/?p=113743

Institute of International Education. (2008). Fall 2008 international student enrollment survey. Retrieved from http://opendoors.iienetwork.org/?p=Fall2008Survey

International Assembly for Collegiate Business Accreditation. (2009). Accreditation manual. Olathe, KS: Author.

Jain, S. C. (2008). Enhancing international business education through restructuring business schools. Journal of Teaching in International Business, 20, 4-34.

Josselson, R., Lieblich, A., \& McAdams, D. P. (Eds.). (2003). Up close and personal: The teaching and learning of narrative research. Washington, DC: American Psychological Association.

Kickul, J., Lester, S., \& Belgio, E. (2004). Attitudinal and behavior outcomes of psychological contract breach: A cross cultural comparison of the United States and Hong Kong Chinese. International Journal of Cross Cultural Management, 4(2), 229-243.

Kirstein, K. D., Fountain, E. A., \& Flores, K. A. (2009). Internationalizing business curricula: An outcomes-focused approach. Business Education Innovation Journal, 1(2), 83-91. 
Knowles, M., Holton, E., \& Swanson, R. (2005). The adult learner: The definitive classic in adult education and human resource development. San Diego, CA: Butterworth-Heinemann.

Kvale, S. (1996). Interviews: An introduction to qualitative research interviewing. Thousand Oaks, CA: Sage.

Lefrere, P. (2007). Competing higher education futures in a globalising world. European Journal of Education, 42(2), 201-212.

Malone, T. (2004). The future of work. Boston, MA: Harvard Business School Press.

Manuel, T., Shooshtari, N. H., Fleming, M. J., \& Wallwork, S. S. (2001). Internationalization of the business curriculum at U.S. colleges and universities. Journal of Teaching in International Business, 12(3), 43-69.

Martinelli, R., Rahschulte, T., \& Waddell, J. (2010). Leading global project teams: The new leadership challenge. Oshawa, ON, Canada: Multi-Media Publications, Inc.

Micklethwait, J., \& Wooldridge, A. (2000). A future perfect: The challenge and bidden promise of globalization. New York, NY: Times Books.

Mintzberg, H. (2004). Managers, not MBA's. San Francisco: Berett-Koehler Publishers.

Mohammed, S., \& Angell, L. C. (2004). Surface- and deep-level diversity in workgroups: Examining the moderating effects of team orientation and team process on relationship conflict. Journal of Organizational Behavior, 25, 1015-1039.

National Intelligence Council. (2008). Global trends 2025: A transformed world. Washington, DC: U.S. Government Printing Office.

Oblinger, D. G., \& Oblinger, J. L. (2005). Educating the net generation. Educause. Retrieved from http://www.educause.edu/educatingthenetgen

Patton, M. Q. (2002). Qualitative research E evaluation methods (3rd ed.). Thousand Oaks, CA: Sage.

Pfeffer, J., \& Fong, C. T. (2002). The end of business schools? Less success than meets the eye. Academy of Management Learning \& Education, 1(1), 78-95.

Prestwich, R., \& Ho-Kim, T. (2007). Knowledge, skills and abilities of international business majors: What we teach them versus what companies need to know. Journal of Teaching in International Business, 19(1), 29-55.

Prestwich, R., \& Ho-Kim, T. (2009). Practical skills in international business: Training needs for workforce competence by Minnesota companies. Journal of Teaching in International Business, 20, 149-173.

Reynolds, J. I., \& Rice, G. H. (1988). American education for international business. Management International Review, 3, 48-57.

Sulaiman, A, \& Mohezar, S. (2008). Quality in an MBA programme: Students' perceptions. International Journal of Management Education, 7(2), 1-8.

Suutari, V., \& Smale, A. (2008). Designing IB curricula for future global careerists: A boundaryless career perspective. Journal of Teaching in International Business, 19(2), 167-191.

Thomas, D., \& Bostrom, R. (2007). Building trust and cooperation through technology adaptation in virtual teams: Empirical field evidence. Information Systems Management, 25, 45-56.

Tuleja, E. (2008). Aspects of intercultural awareness through an MBA study abroad program: Going backstage. Business Communication Quarterly, 71(3), 314-337.

Vincent-Lancrin, S. (2004). Building futures scenarios for universities in higher education: An international approach. Policy Futures in Education, 2, 245-262. 
Yu, C. J., Guan, J., Yang, K., \& Chiao, Y. (2005). Developing the skills for international business management: The implications of the Management Education Opportunity Grid. Journal of Teaching in International Business, 16(4), 5-26.

Zimmerman, A., \& Fey, R. (2001). Undergraduate business education in the People's Republic of China: Adaptation to the market economy. Journal of Teaching in International Business, 12(4).

\section{APPENDIX}

Responses Regarding the Need for Knowledge, Skills, and Abilities

Background in international economics

$1=$ Essential $2=$ Important $3=$ Not needed

International trade theory

Bilateral, multilateral trade agreements

(NAFTA, EU, WTO)

Foreign exchange market, exchange rate regimes

Background in international business

Strategic planning

Joint ventures, foreign investment, branches

Direct sales: Exporting, distributorships

Importing and sourcing or purchasing strategies

Corporate finance (accounting, taxation, financial management)

Export finance (letters of credit, etc.)

Global production (materials management, ISO certification)

Global sales contracts (contracts, negotiation, international law)

Global advertising and marketing (trade leads)

Other global business (R\&D, HR)

Global transportation and logistics (storage, shipping)

Other import/export skills

Global customer service, including after sales

Other related business

Legal areas (IP, distributor agreements)

Export control laws, regulatory compliance, licensing, inspections

Import control laws, regulatory, compliance, licensing, inspections

Business ethics (CR, fair labor practices)

Cultural differences (cross-cultural communications, customs)

Market research methods

Country- or region-specific knowledge

Background checks on foreign companies (due diligence, credit)

\section{Other general}

Computer software skills

Project leadership

Teamwork

Writing skills

Presentation skills

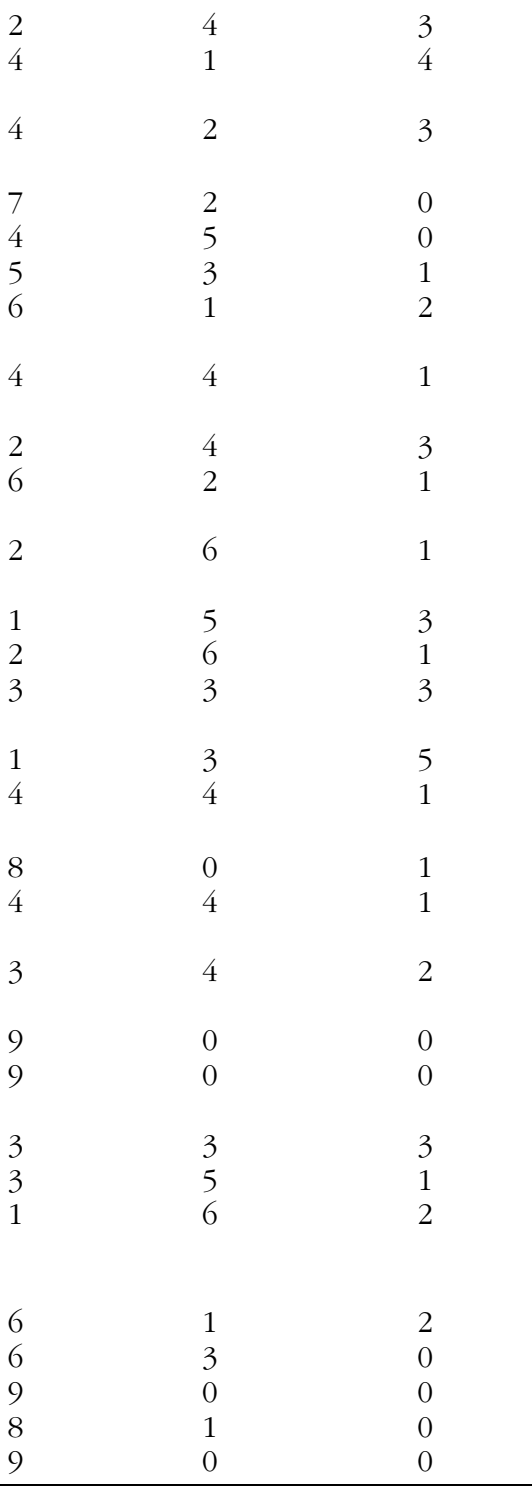

